\title{
INTRODUCTION TO GUEST EDITOR
}

\section{David E. Beck, M.D.}

Dr. David E. Beck is Chairman of the Department of Colon and Rectal Surgery at the Ochsner Clinic in New Orleans, Louisiana. Dave was born in Geneva, Illinois. He received a B.S. degree as a distinguished graduate from the United States Air Force Academy and his M.D. from the University of Miami in Florida. He completed his general surgery residency at Wilford Hall USAF Medical Center at Lackland AFB, Texas. After spending a year as an Air Force general surgeon at a small base in Florida, he completed a fellowship in Colon and Rectal Surgery at the Cleveland Clinic. Dr. Beck then returned to Wilford Hall to serve as the Chief of Colon and Rectal Surgery and eventually as Chairman of the Department of General Surgery. During his Air Force career, he served as the Air Force Surgeon General's consultant in Colon and Rectal Surgery; and during the Gulf War served as Chief of Surgery at the 81st Contingency Hospital located at Little Rissington, United Kingdom. In 1993, he joined the colorectal staff at the Ochsner Clinic and in 1995 became chairman of the department. In 2005, he was elected to the Board of Governors of the Ochsner Clinic.

Dr. Beck maintains a busy clinic practice in New Orleans with major emphasis on endoscopy and laparoscopy. Members of the department perform $~ 8,000$ colonoscopies per year. In addition, Dr. Beck has been a course director and instructor in the annual Association of Program Directors in Colon and Rectal Surgery Laparoscopic Fellows Course since 1991.

Dr. Beck assumed the duties of Editor in Chief of Clinics in Colon and Rectal Surgery in January 2000. He has previously served on the Editorial Board of Diseases of the Colon and Rectum and is also currently the Editor in Chief of The Ochsner Journal. Dr. Beck has been a guest editor of several previous issues of Clinics and is the author and editor of seven textbooks. Those currently in press include Fundamentals of Anorectal Surgery, Improved Outcomes of Colon and Rectal Surgery, Handbook of Colon and Rectal Surgery, the American Society of Colon and Rectal Surgery(ASCRS)Textbook of Colon and Rectal Surgery, and the ASCRS Manual of Colon and Rectal Surgery. He has published more than 100 book chapters and monographs and more than 150 peer-reviewed articles.

Dr. Beck is the president elect of the ASCRS and serves on multiple committees of this society. An active researcher, Dr. Beck received the ASCRS Outstanding Young Investigator's Award in 1992, and is a member of the Board of Trustees of the ASCRS Research Foundation. He is also listed in Best Doctors in America, Who's Who in America, and was selected as one of Good Housekeeping's Top 318 Cancer Doctors for Women.

David Beck and his wife, Sharon, live in Madisonville, Louisiana. When not working, he enjoys fishing, gardening and woodworking.

On behalf of the readers and staff of Clinics in Colon and Rectal Surgery, the editorial board thanks Dr. Beck for serving as Guest Editor and for providing us with a useful issue on urology and gynecology.

David E. Beck, M.D. ${ }^{1}$
Editor in Chief

\footnotetext{
${ }^{1}$ Department of Colon and Rectal Surgery, Ochsner Clinic Foundation, New Orleans, Louisiana.

Address for correspondence and reprint requests: David E. Beck, M.D., Department of Colon and Rectal Surgery, Ochsner Clinic Foundation, 1514 Jefferson Hwy., New Orleans, LA 70121 (e-mail: dbeckmd@aol.com).
}

Urology and Gynecology; Guest Editor, David E. Beck, M.D.

Clin Colon Rectal Surg 2010;23:59-60. Copyright (C) 2010 by Thieme Medical Publishers, Inc., 333 Seventh Avenue, New York, NY 10001, USA. Tel: $+1(212)$ 584-4662.

DOI: http://dx.doi.org/10.1055/s-0030-1254346.

ISSN 1531-0043. 